\title{
Low Temperatures Induce Rough Blossom-end Scarring of Tomato Fruit during Early Flower Development
}

\author{
J.H.M. Barten and J.W. Scott \\ Gulf Coast Research and Education Center, Institute of Food and Agricultural Sciences, Universiy \\ . of Florida, 5007 60th Street East, Bradenton, FL 34203
}

\author{
N. Kedar and Y. Elkind \\ Department of Field Crops, Vegetables and Genetics, The Hebrew University of Jerusalem, P. O. \\ Box 12, Rehovot 76100, Israel
}

Additional index words. Lycopersicon esculentum, fruit malformation, flower differentiation, breeding, catfacing

\begin{abstract}
To identify the stage of flower development sensitive to low temperature-induced rough blossom-end scarring (RBS) in tomato (Lycopersicon esculentum Mill.), short-term low-temperature treatments (1, 3, and 5 days continuously at $10 \mathrm{C}$ or 6,9 , and 12 days at $18 / 10 \mathrm{C}$ day/night) were applied to young, flowering plants and to plants at the six-leaf stage. Flowers were tagged at anthesis over 4 weeks and the growth stage of the flowers at the beginning of the treatments was determined in days relative to anthesis. The blossom-end scar index (BSI), a measure for blossom-end scar size relative to fruit size, and number of locules were recorded for mature fruits. In three experiments, 5 days at $10 \mathrm{C}$ or 6 days at 18/10C, applied during early flower differentiation, induced RBS in mature fruits. For each of the three cultivars tested 'Horizon', Waker', and 'Solar Set'), flower buds were most sensitive from 26 to 19 days before anthesis. In this experiment, RBS induction was not caused by an increase in the average number of locules per fruit. A short period of sensitivity during very early flower development explains the variation in RBS among seasons and within plants encountered in field situations. This study also presents a standard induction technique for further investigation of physiological and morphological backgrounds of the disorder and possible genotype screening.
\end{abstract}

RBS in tomato is characterized by corky tissue at the distal end of the fruit that may contain channels, usually extending into the locules (Fortney, 1958; Sherman and Allen, 1981). RBS is aesthetically undesirable, but more important, the blossom end is sensitive to bruising. Furthermore, channels often leak and form an entrance port for postharvest pathogens, dramatically reducing shelf life (Fortney, 1958; Jones et al., 1969). Catfacing is a severe form of RBS, usually combining a large blossom-end scar with a distorted blossom end and irregular fruit shape (Stevenson and Heimann, 1981). Although many modern cultivars are resistant to catfacing, RBS still is one of the main reasons for rejection of fresh-market tomatoes.

The occurrence of cat facing has been associated with prolonged cool weather early in the growing season (Knavel and Mohr, 1969; Sherman and Allen, 1981; Stevenson and Heimann, 1981). In addition to catfacing, long-term ( $\geq 5$ weeks) low-temperature treatments, applied between cotyledon expansion and anthesis, caused fascination (Sawhney and Polowick, 1985), triangular fruits (Hosoki et al., 1985), navel-like scars, puffiness, seedless fruits (Rylski, 1979), and "strawberry" fruits with split ovary (Asahira et al., 1982). Most of these malformations were attributed to an increase in the number of locules (Asahira et al., 1982; Kaneme and Itagi, 1966; Sawhney and Polowick, 1985). Since each of these experiments involved longterm, low-temperature treatments, many fruits were affected and no detailed information was obtained on the stage of flower development sensitive to low-temperature induction of fruit mal-

Received for publication 9 May 1991. Accepted for publication 28 Oct. 1991. Florida Agricultural Experiment Station Journal Series no. R-01518. This research was supported by grant no. US-993-85 from BARD, The United StatesIsrael Binational Agricultural Research and Development Fund. The cost of publishing this paper was defrayed in part by the payment of page charges. Under postal regulations, this paper therefore must be hereby marked advertisement solely to indicate this fact. formations. Kaneme and Itagi (1966) suggested that fruit malformations could only be induced when low temperatures were applied shortly before or after flower differentiation. Saito and Ito (1971) reported that a low-temperature treatment of 20 days at $9 \mathrm{C}$, starting at the four-leaf stage, resulted in increased locule counts in the first inflorescence. Rylski (1979) indicated that low temperatures (18/9C day/night) induced RBS before, but not after, anthesis.

The purpose of this study was to determine the effect of shortterm low temperatures on RBS induction and to obtain detailed information on the growth stage during flower development that was most sensitive to inducing low-temperature treatments.

\section{Materials and Methods}

Flowering plants (second inflorescence), Spring 1989. 'Horizon' and 'Walter', both susceptible to RBS, were seeded on 19 Jan. and transplanted to trays with $45-\mathrm{ml}$ cells on 27 Jan. The plants were potted in 1.6-liter pots on 10 Mar. and grown in a greenhouse until one to two flowers of the second inflorescence reached anthesis. On 6 Apr. the plants were moved into growth chambers and treated as follows: 1) Control; 6 days at 22/17C (day/night); 2) 1 day at 22/17C, 1 day at 10/10C, 4 days at 22/17C; 3 ) 1 day at 22/17C, 3 days at 10/10C, 2 days at 22/17C; and 4) 1 day at 22/17C, 5 days at 10/10C. The plants were illuminated for $12 \mathrm{~h} \cdot \mathrm{day}^{-1}$ with gro-lux and cool-white tubes at an average photosynthetic photon flux of 170 $\mu \mathrm{mol} \cdot \mathrm{m}^{-2} \mathrm{~s}^{-1}$. Twelve plants of each cultivar per treatment were planted in the field on 12 Apr. Flowers were tagged at anthesis so that the growth stage of each flower at the beginning of the temperature treatments could be derived in days relative to anthesis. The flowers were tagged from 1 until 30 Apr. Ma-

Abbreviations: BSI, blossom-end scar index; RBS, rough blossom-end scarring. 
ture fruits were harvested and the blossom-end scar size was measured, relative to fruit size as follows:

$$
\mathrm{BSI}=\frac{\sqrt{\mathrm{a} \times \mathrm{b}}}{\sqrt{\mathrm{c} \times \mathrm{d}}} \times 100
$$

with $\mathrm{BSI}=$ blossom-end scar index, $\mathrm{a}=$ largest diameter of blossom-end scar, $\mathrm{b}=$ smallest diameter of blossom-end scar, $\mathrm{c}=$ largest diameter of equatorial fruit cross section, $\mathrm{d}=$ smallest diameter of equatorial fruit cross section. Measurements of scar and fruit size were taken using an electronic caliper (Ultra-Cal, accuracy $\pm 0.03 \mathrm{~mm}$; Fowler Sylvac, Newton, Mass.) with a portable interface and datalogger (" $1 \times 8$ " Gage Talker plus; Fowler), and downloaded to a microcomputer for data analysis. The number of locules and anthesis date were also recorded.

Flowering plants (first inflorescence), Spring 1990. The recently released heat tolerant cultivar Solar Set (Scott et al., 1989) was seeded on 5 Jan., transplanted to trays with 45-ml cells on 17 Jan., potted in 0.35-liter pots on 3 Feb., and transplanted to 1.6-liter pots on 16 Mar. The plants were grown in a greenhouse until one flower on the first inflorescence was at or close to anthesis. Starting on 28 Mar., the following treatments were applied to 16 plants per treatment: 1) Greenhouse control, 12 days at ambient temperatures (average maximum: 32.5C; average minimum: $18.5 \mathrm{C}$ ) and daylight in greenhouse; 2) Growth chamber control, 12 days at $29 / 18 \mathrm{C}$ in growth chamber; 3) 6 days at 18/10C, 6 days at $29 / 18 \mathrm{C}$ in growth chamber; and 4) 9 days at $18 / 10 \mathrm{C}, 3$ days at ambient temperatures in growth chamber. The 'low-temperature treatments were milder than in 1989 and similar to field temperatures during a cold spell in Florida. A growth chamber malfunction on 6 Apr. interrupted the last treatment that would have been 12 days at 18/ 10C. The illumination in the growth chambers was the same as in 1989. Flowers were tagged from 27 Mar. until 30 Apr., and on 9 Apr. the plants were transplanted to greenhouse beds. BSI and anthesis date were recorded for mature fruits.

Six-leaf stage, Fall 1990., 'Solar Set' was seeded on 30 July, transplanted to trays with $45-\mathrm{ml}$ cell volume on 8 Aug., and potted in 0.35-liter pots on 19 Aug. The plants were kept in a greenhouse until the sixth true leaf had fully expanded. On 26 Sept., plants were moved into the growth chamber and lowtemperature treatments were applied to 29 plants per treatment as follows: 1) Control, 12 days at $29 / 18 \mathrm{C}$; 2) 6 days at $18 / 10 \mathrm{C}$, 6 days at 29/18C; 3) 9 days at 18/10C, 3 days at 29/18C; and 4) 12 days at $18 / 10 \mathrm{C}$. Illumination in the growth chamber was as described. The plants were planted in greenhouse beds on 8 Oct., and flowers were tagged from 21 Oct. until 5 Nov. BSI and anthesis date were recorded at maturity. This large scale induction experiment was conducted to obtain more fruits per individual anthesis date.

Experiment design and data analysis. Greenhouse and field experiments were conducted in Bradenton, Fla. The plants were tested in a completely randomized design (CRD), and data for individual fruits were analyzed following an unbalanced CRD. From the anthesis date and the starting date of the temperature treatments, the growth stage at the beginning of the temperature treatments was determined in days relative to anthesis for individual fruits. In 1989, each growth stage consisted of a 3-day interval; in Spring 1990, 5-day intervals were used, because in the latter experiment fewer fruits were available for a wider range of anthesis dates. The experiment in Fall 1990 was large enough to analyze individual anthesis dates. In Spring 1989, the model used was:

$$
\begin{aligned}
Y_{i j k l}=\mu+\alpha_{i}+\beta_{j} & +\gamma_{k}+\alpha \beta_{i j} \\
& +\alpha \gamma_{i k}+\beta \gamma_{j k}+\alpha \beta \gamma_{i j k}+\epsilon_{i j k l}
\end{aligned}
$$

with $\mathrm{Y}_{\mathrm{ijkl}}=\mathrm{BSI}$ of fruit $\mathrm{I}$ from cultivar $\mathrm{k}$ with temperature treatment $i$ and growth stage $j ; \mu=$ mean; $\alpha_{i}=$ temperature treatment effect; $\beta_{j}=$ growth stage effect; $\gamma_{k}=$ cultivar effect; $\alpha \beta_{\mathrm{ij}}, \alpha \gamma_{\mathrm{ik}}, \beta \gamma_{\mathrm{jk}}$, and $\alpha \beta \gamma_{\mathrm{ijk}}=$ interaction effects; and $\epsilon_{\mathrm{ijkl}}=$ error. In the 1990 experiments, the model was:

$$
Y_{i j k}=\mu+\alpha+\beta_{j}+\alpha \beta_{i j}+\epsilon_{i j k}
$$

with $\mathrm{Y}_{\mathrm{i} \mathrm{j}}=\mathrm{BSI}$ of fruit $\mathrm{k}$ with temperature treatment $\mathrm{i}$ and growth stage $\mathrm{j}$. The other symbols are as indicated for model [1]. PROC GLM of Statistical Analysis System (SAS Institute, Cary, N.C.) was used for analysis of variance (ANOVA) and the LSMEANS statement was used to obtain least squares means. Pairwise comparisons between temperature treatments at fixed levels of growth stage and cultivar effects were made using CONTRAST statements in PROC GLM (Freund et al., 1986). Multiple range tests were constructed from pairwise comparisons with $\alpha / \mathrm{n}$ as the level of significance for individual pairwise comparisons, where $\alpha$ is the level of significance for the multiple range test and $\mathrm{n}$ is the number of pairwise comparisons possible.

\section{Results}

In all experiments, 4 to 5 days after the start of the lowtemperature treatments, anthocyanin had accumulated in the veins and stems of the plants, and the leaves were dark green. The control plants were taller than those of the other treatments. Two weeks after the end of the treatments, no difference in plant appearance was noticeable between treatments. The lowtemperature treatments did not influence the average number of

\begin{tabular}{|c|c|c|c|c|}
\hline Experiment & Cultivar & $\begin{array}{c}\text { Temp } \\
\text { treatment }\end{array}$ & $\begin{array}{c}\text { Plants } \\
\text { (no.) }\end{array}$ & $\begin{array}{c}\text { Fruits } \\
\text { (no.) }\end{array}$ \\
\hline \multirow[t]{8}{*}{ Spring 1989} & \multirow[t]{4}{*}{ Horizon } & Control $^{z}$ & 12 & 175 \\
\hline & & 1 day $10 \mathrm{C}$ & 12 & 179 \\
\hline & & 3 days $10 \mathrm{C}$ & 12 & 168 \\
\hline & & 5 days $10 \mathrm{C}$ & 12 & 177 \\
\hline & \multirow[t]{4}{*}{ Walter } & Control $^{2}$ & 12 & 180 \\
\hline & & 1 day $10 \mathrm{C}$ & 12 & 153 \\
\hline & & 3 days $10 \mathrm{C}$ & 12 & 162 \\
\hline & & 5 days $10 \mathrm{C}$ & 12 & 164 \\
\hline \multirow[t]{5}{*}{ Spring 1990} & \multirow[t]{5}{*}{ Solar Set } & Greenhouse & $1^{y} 16$ & 140 \\
\hline & & Growth chamber & & \\
\hline & & $\operatorname{control}^{x}$ & 16 & 107 \\
\hline & & 6 days $18 / 10 \mathrm{C}$ & 16 & 138 \\
\hline & & 9 days $18 / 10 \mathrm{C}$ & 16 & 138 \\
\hline \multirow[t]{4}{*}{ Fall 1990} & \multirow{4}{*}{ Solar Set } & Control $^{x}$ & 29 & 182 \\
\hline & & 6 days $18 / 10 \mathrm{C}$ & 29 & 215 \\
\hline & & 9 days $18 / 10 \mathrm{C}$ & 29 & 190 \\
\hline & & 12 days $18 / 10 \mathrm{C}$ & 29 & 196 \\
\hline
\end{tabular}
fruits harvested per plant (Table 1). Of the fruits in each ex-

Table 1. The number of tomato plants and fruits analyzed for each temperature induction experiment.

${ }^{2}$ Control plants and treated plants were kept at $22 / 17 \mathrm{C}$ until all lowtemperature treatments were completed.

${ }^{y}$ Plants were kept at ambient temperatures in a greenhouse.

${ }^{\times}$Control plants and treated plants were kept at 29/18C until all lowtemperature treatments were completed. 
periment, $0 \%$ to $1 \%$ were fasciated regardless of treatment and eliminated from the analysis. The occurrence of beaky (i.e., exhibiting pointed blossom ends) and puffv fruits on some of the plant in the greenhouse was unrelated to the cold treatments, and these fruits were included in the analysis.

Flowering plants (second inflorescence), Spring 1989. In this experiment there was no difference in earliness, expressed as days from seeding to anthesis, between 'Horizon' and 'Walter'. ANOVA for BSI and number of locules according to model [1] indicated significant $\alpha=0.05)$ temperature treatment $\times$ growth stage interaction (Table 2), suggesting that the low-temperature treatments only affected flowers at a particular growth stage. Significance of the growth stage $\mathrm{x}$ cultivar interaction (Table 2) may indicate a difference between 'Horizon' and 'Walter' in sensitivity to the low-temperature treatments. For each combination of temperature treatment, growth stage, and cultivar, the least squares means for BSI and number of locules were calculated and plotted (Fig. 1). For each combination of cultivar and growth stage, multiple range tests were constructed from

Table 2. ANOVA for BSI and number of locules per tomato fruit for the temperature induction experiment in Spring 1989.

\begin{tabular}{|c|c|c|c|c|c|c|}
\hline \multirow[b]{2}{*}{ Source } & \multicolumn{3}{|c|}{ BSI } & \multicolumn{3}{|c|}{ Locules (no.) } \\
\hline & $\mathrm{df}$ & MS & $P$ value & df & MS & $P$ value \\
\hline Temp treatment & 3 & 12.28 & 0.496 & 3 & 1.25 & $\overrightarrow{0.530}$ \\
\hline Growth stage & 9 & 422.59 & $<0.001$ & 9 & 43.54 & $<0.001$ \\
\hline Cultivar & 1 & 74.38 & 0.028 & 1 & 575.29 & $<0.001$ \\
\hline $\begin{array}{l}\text { Treatment } x \\
\text { growth stage }\end{array}$ & 27. & 33.09 & $<0.001$ & 27 & 2.59 & 0.043 \\
\hline $\begin{array}{l}\text { Treatment } \times \\
\text { cultivar }\end{array}$ & 3 & 5.48 & 0.786 & 3 & 0.22 & 0.942 \\
\hline $\begin{array}{l}\text { Growth stage } \times \\
\text { cultivar } \\
\text { Treatment } \times \text { stage }\end{array}$ & 9 & 49.60 & $<0.001$ & 9 & 6.72 & $<0.001$ \\
\hline $\begin{array}{l}\quad \times \text { cultivar } \\
\text { Error } \\
\text { Total }\end{array}$ & $\begin{array}{r}27 \\
1278 \\
1357\end{array}$ & $\begin{array}{r}8.63 \\
15.43\end{array}$ & 0.967 & $\begin{array}{r}27 \\
1265 \\
1344\end{array}$ & $\begin{array}{l}2.14 \\
1.70\end{array}$ & 0.169 \\
\hline
\end{tabular}

pairwise comparisons between temperature treatments as described (Fig. 1).

For 'Horizon' fruits that were 23 to 21 days before anthesis at the beginning of the cold treatment, 5 days at $10 \mathrm{C}$ induced significantly larger blossom-end scars than the other treatments (Fig. 1A). 'Walter' reacted similarly to cold exposure, although 3 days at $10 \mathrm{C}$ had an intermediate effect (Fig. 1C). 'Horizon' and 'Walter' fruits that were 4 to 6 days past anthesis at the beginning of the cold treatment had increased BSI for all treatments (Fig. $1 \mathrm{~A}$ and C). These fruits were at anthesis on 1-3 Apr. and 25 to 23 days before anthesis at the beginning of a cold spell that lasted from 9-12 Mar. (Fig. 2). This cold spell probably induced RBS in all plants, regardless of low-temperature treatments applied later. Thus, in this experiment, two lines of evidence indicated that flower buds were most sensitive to induction of RBS by low temperatures 25 to 21 days before anthesis. At this growth stage, flower initials are not visible without magnification. Five days at 10C induced increased RBS without causing severe low temperature-related disorders.

The pattern for average number of locules per fruit (Fig. $1 \mathrm{~B}$ and D) deviated markedly from that for BSI (Fig. 1 A and C). The average number of locules in 'Horizon' fruit was not affected by the low-temperature treatments (Fig. 1B). The average number of locules was high for all treatments in 'Walter' fruits that were 2 days before to 3 days after anthesis at the beginning of the cold treatment (Fig. 1D). These fruits were at anthesis on 4-9 Apr. and 31 to 26 days before anthesis at the beginning of the cold spell in March, which may have caused this effect. Increased average BSI values did not coincide with increased average locule counts, indicating that, in this experiment, RBS induction was not caused by an increased number of locules was not a direct cause of RBS in this experiment.

Flowering plants (first inflorescence), Spring 1990. This experiment was designed to further investigate the significant temperature effects at the left edge of the graphs in Fig. $1 \mathrm{~A}$ and C. No confounding climatic conditions interfered with the lowtemperature treatments. ANOVA for BSI according to model [2] indicated a significant temperature treatment $\mathbf{x}$ growth stage
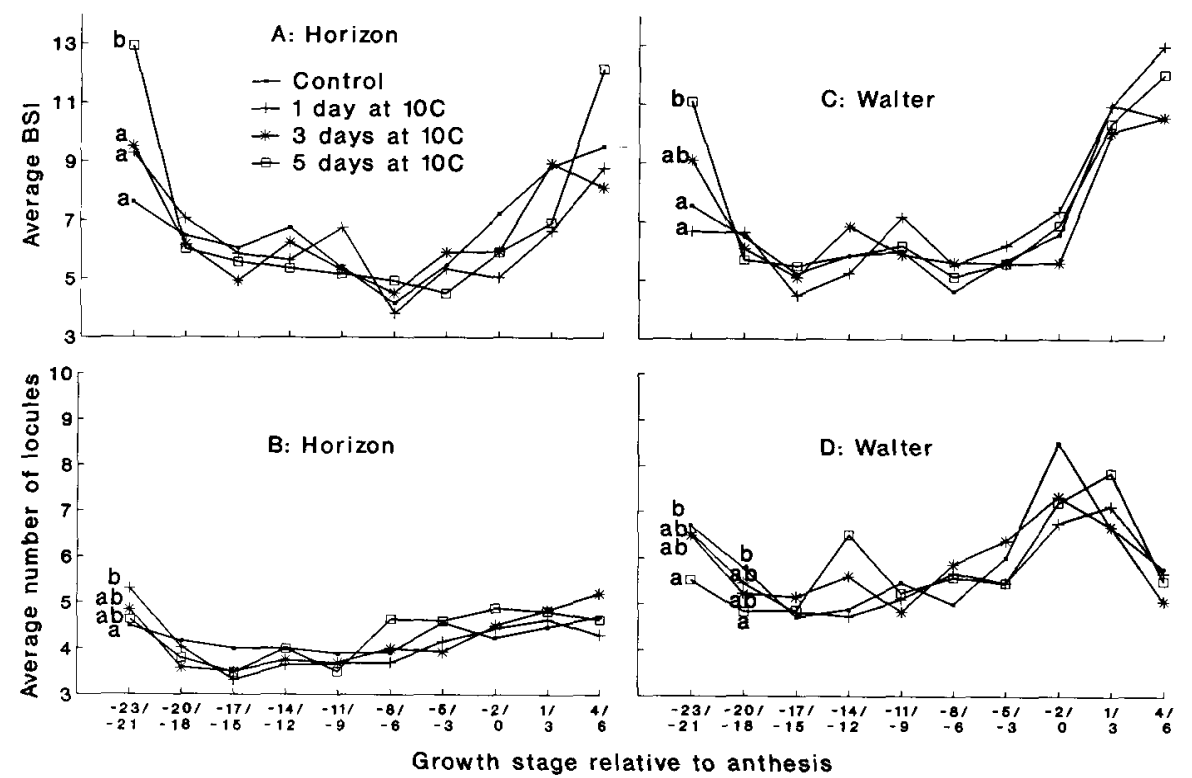

Fig. 1. Influence of low-temperature treatments on 'Horizon' $(\mathbf{A}, \mathbf{B})$ and 'Walter' $(\mathbf{C}, \mathbf{D})$ flowers at various growth stages, expressed in days relative to anthesis, with negative and positive values indicating days before and after anthesis, respectively. Mean separation within a growth stage at $\alpha=0.05$. Each data point represents an average of at least five fruits. 


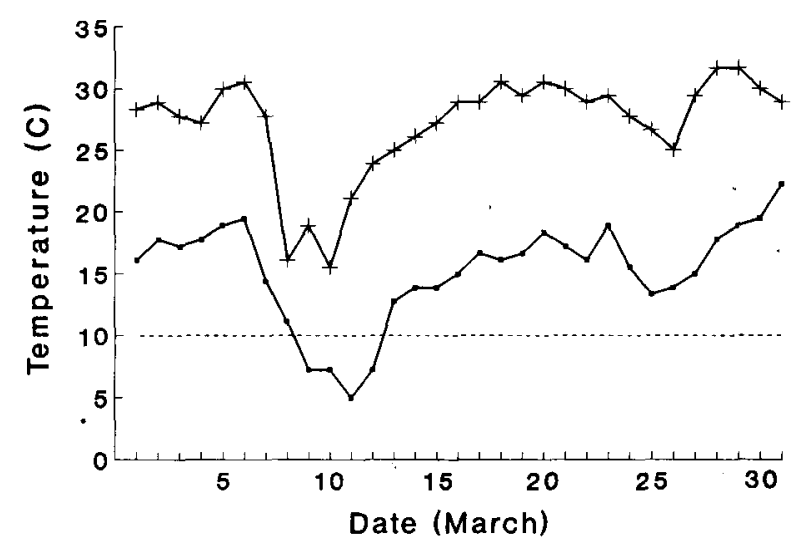

Fig. 2. Minimum (ロ) and maximum (+) daily temperatures for Mar. 1989 , in the greenhouse where 'Walter' and 'Horizon' plants were grown before temperature treatments were applied.

Table 3. ANOVA for BSI per tomato plant for the temperature induction experiments in 1990.

\begin{tabular}{|c|c|c|c|c|c|c|}
\hline \multirow[b]{2}{*}{ Source } & \multicolumn{3}{|c|}{$\begin{array}{c}\text { Flowering plants } \\
\text { (Spring 1990) }\end{array}$} & \multicolumn{3}{|c|}{$\begin{array}{l}\text { Six-leaf stage } \\
\text { (Fall 1990) }\end{array}$} \\
\hline & $\mathrm{df}$ & MS & $P$ value & $\mathrm{df}$ & MS & $P$ value \\
\hline Temp treatment & 3 & 1.93 & 0.817 & 3 & 38.03 & $<0.001$ \\
\hline Growth stage & 6 & 34.26 & $<0.001$ & 15 & 14.65 & $<0.001$ \\
\hline \multicolumn{7}{|l|}{ Treatment $x$} \\
\hline growth stage & 18 & 14.34 & 0.002 & 41 & 7.60 & $<0.001$ \\
\hline Error & 495 & 6.19 & & 723 & 2.27 & \\
\hline Total & 522 & & & 782 & & \\
\hline
\end{tabular}

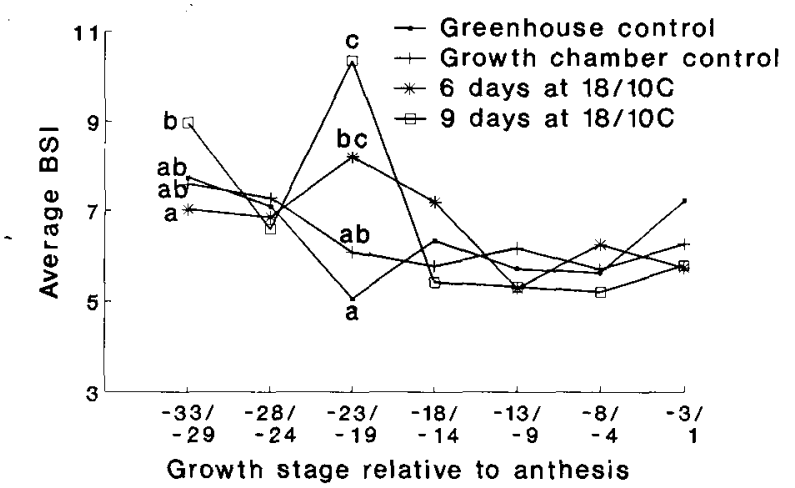

Fig. 3. Influence of low-temperature treatments on 'Solar Set' flowers at various growth stages, expressed in days relative to anthesis, with negative and positive values indicating days before and after anthesis, respectively. Mean separation within a growth stage at $\alpha$ $=0.05$. Each data point represents an average of at least five fruits.

interaction (Table 3), suggesting sensitivity of a particular growth stage to low temperatures. For each combination of temperature treatment and growth stage, the least squares means for BSI were calculated and plotted (Fig. 3). Comparison of BSI between low-temperature treatments within each growth stage indicated that only fruits that were 23 to 19 days before anthesis at the beginning of the treatments were sensitive to induction of RBS by low temperatures. Nine days at $18 / 10 \mathrm{C}$ induced significantly larger blossom-end scars than the control treatments, whereas 6 days at $18 / 10 \mathrm{C}$ had an intermediate effect on fruits that were 23 to 19 days before anthesis at the beginning of the treatments (Fig. 3). Although fruits that were 33 to 29 days before anthesis had a high average BSI value for the 9day cold treatment, this value was not significantly different from the BSI values for the control treatments (Fig. 3). The average BSI did not differ significantly between the two control treatments (Fig. 3), indicating that the transfer of plants from greenhouse to growth chamber did not influence blossom-end scarring.

Six-leaf stage, Fall 1990. ANOVA for BSI according to model [2] indicated a significant temperature treatment $\mathrm{x}$ growth stage interaction (Table 3). Least squares means were calculated for BSI per combination of growth stage and temperature treatment, and multiple range tests were constructed for the temperature treatments within each growth stage (Fig. 4). The plants in the 9- and 12-day cold treatments flowered 3 and 2 days later than those of the other treatments, respectively (Fig. 4). Flower bud differentiation was delayed for all treatments, and at least two extra leaves developed between the cotyledons and the first inflorescence, probably due to high temperatures shortly after cotyledon expansion (Calvert, 1957). Although the flowers were younger than anticipated at the beginning of cold treatments (the. oldest flowers were 25 days before anthesis, the data in Fig. 4 were in agreement with the previous experiments. Six days at 18/10C significantly increased BSI over the control treatment for fruits that were 25 and 26 days before anthesis at the beginning of the treatments (Fig. 4). Nine days at 18/10C significantly increased BSI over the control treatment for fruits that were 28 days before anthesis at the beginning of the treatments (Fig. 4). Thus, flowers that were sensitive to the 9-day treatment were 2 days younger at the beginning of the treatment than the flowers that were sensitive to the 6-day treatment. A possible explanation is that these young flowers grew into the sensitive stage (26 days before anthesis) during the 9-day treatment and subsequently received 6 days at 18/10C. Similarly, 12 days at $18 / 10 \mathrm{C}$ induced significantly increased levels of BSI in flowers that were 32 days before anthesis or older at the beginning of the treatments (Fig. 4). This pattern fits the hypothesis that these young flowers grew into the sensitive stage ( 26 days before anthesis) during the 12-day treatment and subsequently received 6 days at 18/10C. If flowers were sensitive to 6 days at 18/10C earlier than 26 days before anthesis, then the 6-day treatment should have affected these earlier stages as well. The conclusion from this experiment was that 6 days at $18 / 10 \mathrm{C}$ was enough to induce RBS and that flowers were sensitive to RBS-inducing temperatures no earlier than 26 days before anthesis. The intermediate effect of 6 days at $18 / 10 \mathrm{C}$ on flowers 23 to 19 days

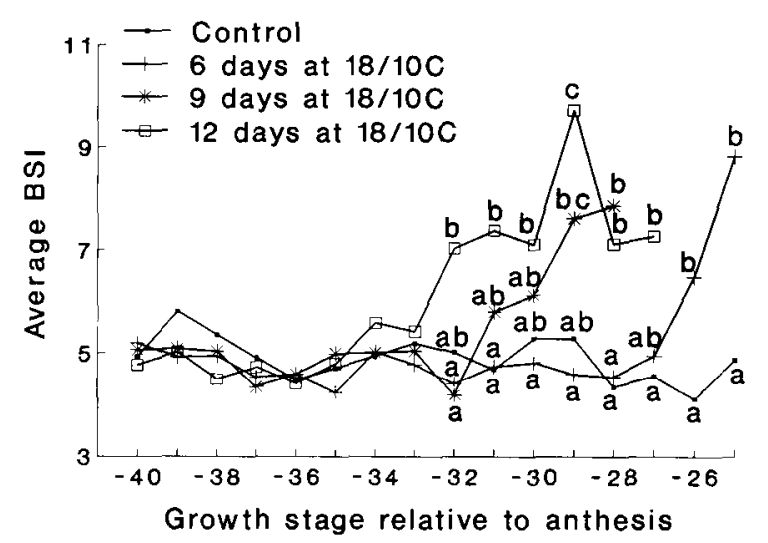

Fig. 4. Influence of low-temperature treatments on 'Solar Set' flowers at various growth stages, expressed in days relative to anthesis, with negative and positive values indicating days before and after anthesis, respectively. Mean separation within a growth stage at $\alpha$ $=0.05$. Each data point represents an average of at least five fruits. 
before anthesis in Spring 1990 (Fig. 3) may have been due to pooling of anthesis dates.

\section{Discussion}

In each experiment, flowers were sensitive to low temperature-induced RBS for only a short period during their development. Five days continuously at $10 \mathrm{C}$ or 6 days at $18 / 10 \mathrm{C}$ were sufficient to induce RBS. These results explain the variation in expression of RBS over seasons and within plants often occurring in field situations (Elkind et al., 1990). The long time interval between induction and visible response explains why it has been hard to relate the occurrence of RBS to temperature fluctuations. For the fruits that underwent inducing temperatures and developed in the field, the percentage unmarketable fruits (scar length > $1 \mathrm{~cm}$; Wien and Zhang, 1991) was 35\% and $31 \%$ in 'Horizon' and 'Walter', respectively (1989 experiment). Thus, if climatic conditions are inductive, losses due to RBS can be quite extensive. The sensitive period was 26 to 19 days before anthesis and very similar in experiments involving three growing seasons, three cultivars, grown in field or greenhouse beds. This information may be used in field situations to investigate whether genotypes are sensitive to low-temperature induction of RBS. Three weeks after a cold spell, flowers can be tagged at anthesis, and blossom-end scar size on mature tagged fruits can then be evaluated for different genotypes. This method of focusing observations during selection will help in breeding for smooth blossom-end scars. Recent genetic studies indicated predominantly additive inheritance of blossom-end scar size (Barten, 1991; Barten et al., 1992a) and significant but relatively unimportant genotype' $x$ environment interactions (Barten et al., 1992a; Elkind et al., 1990).

This study presents a standard induction technique for further physiological studies or genotype screening. A short, mild, lowtemperature treatment ( 6 days at $18 / 10 \mathrm{C}$ ) will induce RBS without affecting plant development (Knavel and Mohr, 1969; Sawhney and Polowick, 1985), reducing fruit set (Wien and Zhang, 1991), or causing severe temperature-related fruit malformations. Temperature treatments are effective only after flowers have been initiated, usually at the three-to four-leaf stage (Hurd and Cooper, 1970). After cold exposure, plants can be grown in greenhouse beds or the field. When plants were grown in pots in a greenhouse after temperature induction, BSI did not increase over control treatments (data not shown). Apparently, RBS induction treatments are more effective in a post-treatment environment that is favorable for vigorous growth and development. Research by K. Abel, R. Aker, and N.K. (1987, unpublished results) indicated that low-temperature induction treatments may be helpful in genotype screening. They found that a low-temperature treatment $(17 / 12 \mathrm{C})$ from cotyledon expansion until flowering induced significant differences in BSI among five genotypes, indicative of their performance in field situations. In the induction experiment of Fall 1990, 9 days at 18/10C did not result in increased BSI values for fruits that were at the sensitive stage in 'Valerie', resistant to RBS under field conditions (data not shown due to few fruit).

Studies of tomato flower ontogeny indicated that sepals are differentiated and the corolla starts developing 26 days before anthesis (Chandra Sekhar and Sawhney, 1984; Saito and Ito, 1971; Smith, 1935). At 19 days before anthesis, stamens and carpels start to differentiate. Thus, low temperatures induce RBS very early during differentiation of the ovary. Knavel and Mohr (1969), studying severe catfacing induced by a 5-week lowtemperature (13/6C) treatment during seedling growth, reported breakdown of tissue at the stylar base sometime before anthesis. Further studies are needed to characterize initiation of RBS at the cellular level. Previous studies suggested that the number of locules per fruit is determined shortly after flower bud initiation (Kaneme and Itagi, 1966; Saito and Ito, 1971). In the present study, low temperatures may have induced an increase in the number of locules in 'Walter' flowers during initial flower differentiation (31 to 26 days before anthesis). It seems that, during flower differentiation, the number of locules is determined before blossom-end scar size; however, more work is needed to further substantiate this hypothesis.

The small changes in the number of locules observed in the present study (Fig. 1) are in strong contrast to the results of Saito and Ito (1971), who reported that 6 days at 17/8C induced doubling of the average number of locules per fruit in their material. Multilocular genotypes, with eight to 16 locules, like those used by Saito and Ito (1971), apparently were more sensitive to low temperature-induced locule proliferation than genotypes with only a few (three to seven) locules per fruit (Asahira et al., 1982; Rylski, 1979; Sawhney and Polowick, 1985). In the present experiment, increases in average BSI did not coincide with increases in the average number of locules in the same fruit (Fig. 1). These results agree with a related study in which application of gibberellic acid $\left(\mathrm{GA}_{3}\right)$ and 4-chlorophenoxyacetic acid to young, flowering 'Horizon' and 'Solar Set' plants affected the average BSI, but not the average number of locules (Barten et al., 1992b). Further, investigation of an array of 17 cultigens, varying in sensitivity to RBS induction, indicated that the average BSI per genotype was unrelated to the average number of locules $(r=0.13$; Barten, 1991). Apparently, factors other than the number of locules play a role in RBS induction. However, these results do not reject the possibility that induction of locule proliferation also causes RBS due to mechanical stress during fruit growth, especially in multilocular genotypes. Wien and Zhang (1991) reported that foliar sprays of $4.3 \cdot 10^{-5}$ $\mathrm{M} \mathrm{GA}_{3}$ twice weekly for 3 weeks after transplanting, low temperatures (21/10C day/night) for 3 weeks after transplanting, or topping at transplanting induced locule proliferation and RBS in the multilocular cultivar Celebrity (eight to 10 locules). Wien and Zhang (1991) started their treatments between the two- and three-leaf stage, and RBS was induced in fruits of the first three clusters. Wien and Turner (1991) reported that 2 weeks at 16/ $10 \mathrm{C}$, starting at the six-leaf stage, induced RBS in fruits of the second and third but not the first cluster. Although in this work anthesis dates were not recorded, the sensitive period during flower development seemed to precede the developmental stage that was sensitive to low-temperature RBS induction in the present experiment. It is possible that locule proliferation causes RBS in multilocular genotypes, explaining sensitivity during early stages of flower differentiation. Alternatively, low-temperature treatments, lasting for $\geq 3$ weeks, may induce locule proliferation as well as RBS, although the sensitive period during flower differentiation is not the same for these two processes.

\section{Literature Cited}

Asahira, T., T. Hosoki, and K. Shinya. 1982. Regulation of low temperature-induced malformation of tomato fruit by plant growth regulators. J. Jpn. Soc. Hort. Sci. 50:468-474.

Barten, J. H. M., Y. Elkind, J.W. Scott, S. Vidavski, and N. Kedar. 1992a. Diallel analysis over two locations for blossom-end scar size in tomato. Euphytica. (In press.)

Barten, J.H.M, J.W. Scott, N. Kedar, and Y. Elkind. 1992b. The influence of gibberellic acid and 4-chlorophenoxyacetic acid treat- 
ment of young, flowering plants on blossom-end scar size of tomato fruit. Scientia Hort. (In press.)

Barten, J.H.M. 1991. Genetic, environmental, and physiological factors influencing blossom-end scar size in tomato. PhD Diss., Univ. of Florida, Gainesville.

Calvert, A. 1957. Effect of the early environment on development of flowering in the tomato. I. Temperature. J. Hort. Sci. 32:9-17.

Chandra Sekhar, K.N. and V.K. Sawhney. 1984. A scanning electron microscope study of the development and surface features of floral organs of tomato (Lycopersicon esculentum). Can. J. Bet. 62:24032413.

Elkind, Y., O.B. Galper, S. Vidavski, J.W. Scott, and N. Kedar. 1990. Genetic variation and heritability of blossom-end scar size in tomato. Euphytica 50:241-248.

Fortney, W.R. 1958. Genetic and anatomical studies of imperfect stylar scar formation in tomatoes. PhD Diss., Purdue Univ., Lafayette, Ind.

Freund, R. J., R.C. Littell, and P.C. Spector. 1986. SAS-systems for linear models, 1986 edition. SAS Institute, Inc., Cary, N.C.

Hosoki, T., K. Ohta, T. Asahira, and K. Ohta. 1985. Relationship between endogenous hormone and nutrient levels in shoot apices of tomato and occurrence of fruit malformation and its control by auxin spray and nutritional restrictions. J. Jpn. Soc. Hort. Sci. 54:351356.

Hurd, R.G. and A.J. Cooper. 1970. The effect of early low temperature treatment on the yield of single-inflorescence tomatoes. J. Hort. Sci. 45:19-27.

Jones, J. P., G.F. Weber, and D.G.A. Kelbert. 1969. Tomato diseases in Florida. Fla. Agr. Expt. Sta. Bul. 731.

Kaneme, T. and T. Itagi. 1966. Experiment on the control of deformed fruits in the tomatoes. I. Effect of temperature and vigor of seedlings in nursery term on the appearance of deformed fruit. Bul. Kanagawa Hort. Expt. Sta. 14:57-64.

Knavel, D.E. and H.C. Mohr. 1969. Some abnormalities in tomato fruits as influenced by cold treatment of seedlings. J. Amer. Soc. Hort. Sci. 94:411-413.

Rylski, I. 1979. Effect of temperatures and growth regulators on fruit malformation in tomato. Scientia Hort. 10:27-35.

Saito, T. and H. Ito. 1971. Studies on the growth and fruiting in the tomato. XI. Effect of temperature on the development of flower, especially that of the ovary and its locule. J. Jpn. Soc. Hort. Sci. 40:128-138.

Sawhney, V.K. and P.L. Polowick. 1985. Fruit development in tomato: The role of temperature. Can. J. Bet. 63: 1031-1034.

Scott, J.W., S.M. Olson, H.H. Bryan, T.K. Howe, P.J. Stoffella, and J.A. Bartz. 1989. Solar Set. A heat tolerant, fresh market tomato hybrid. Fla. Agr. Expt. Sta. Bul. S-359.

Sherman, M. and J.J. Allen. 1981. Blossom-end disorders of Florida tomatoes. Proc. Fla. State Hort. Soc. 94:283-284.

Smith, O. 1935. Pollination and life-history studies of the tomato (Lycopersicon esculentum Mill.). Cornell Univ. Agr. Expt. Sta. Mere. 184:3-16.

Stevenson, W.R. and M.F. Heimann. 1981. Tomato (Lycopersicon esculentum) disorder: Catface. Wise. Coop. Ext. Pub. A3111.

Wien, H.C. and A.D. Turner. 1991. Plant age at catface induction determines severity of the disorder. HortScience 26:711-712.

Wien, H.C. and Y. Zhang. 1991. Gibberellic acid foliar sprays show promise as screening tool for tomato fruit catfacing. HortScience 26:583-585. 